\title{
On the Occasion of the Fiftieth Volume of the Scripta Medica (Banja Luka)
}

\author{
Miloš P Stojiljković1,2
}

\section{ABSTRACT}

The article is written by the current Editor-in-Chief of the scientific journal Scripta Medica (Banja Luka) on the occasion of publishing the final issue of the fiftieth volume of the journal. Founded in 1966, the Scripta Medica (Banja Luka) started as a local journal of the Banja Luka Medical Centre, its General Hospital, later belonging to the Association of Medical Doctors of the Bosnian Krajina region and the Republic of Srpska and the Faculty of Medicine, University of Banja Luka. Its eight editors were: Professor Andrija Mikeš (1966-1968), Dr Dragomir Todorović (1969-1971), Assistant Professor Zvonimir Klepac (1972-1974), Professor Branko Pikula (1975-1990), Professor Bogdan Žigić (1995-2009), Professor Rajko Igić (2010-2013), Professor Predrag Grubor (2014-2018) and Professor Miloš P Stojiljković (since 6 August 2018). It used to appear twice a year or quarterly. The Scripta Medica (Banja Luka) has a peer-review process and tends to reach a status of well-established scientific journal.

Key words: medical journal, editors, scientific journal, medicine, dental medicine, pharmacy.
(1) Editor-in-Chief, Scripta Medica (Banja Luka)

(2) Department of Pharmacology, Toxicology and Clinical Pharmacology, Centre for Biomedical Research, Faculty of Medicine, University of Banja Luka, Banja Luka, the Republic of Srpska, Bosnia and Herzegovina.

Correspondence:

MILOŠ P STOJILJKOVIC

E: milos.stojljkkovic@med.unibl.org

ARTICLE INFO

Received: 16 December 2019 Accepted: 18 December 2019
It is a special occasion for every journal when it reaches the 5oth volume. The same applies to the Scripta Medica (Banja Luka) that with the issue 4 completes the fiftieth volume. The geographical descriptor "Banja Luka" is added since the journal, started in 1966, had its namesake from Brno, the Czech Republic, published by the Faculty of Medicine, Masaryk University, which was started in 1922 and, regrettably, ended in 2010.

In the tumultuous history of Banja Luka and the whole region, the journal Scripta Medica (Banja Luka) had its ups and downs that resulted in certain periods of discontinuity in publication. As a result, in these 54 years since its first appearance in May 1966, there were 50 volumes. The main break was during the latest wars in the Balkans that resulted in the decomposition of Yugoslavia and ensued in the aftermath of this process (1991-1994). As a result of this, the journal had two important dates; one in 2016, when the Editor-in-Chief Professor Predrag Grubor cele- brated the $50^{\text {th }}$ anniversary of the foundation of the journal ${ }^{1}$ and the current one, when we commemorate the publishing of its $50^{\text {th }}$ volume.

The Scripta Medica (Banja Luka) was started in 1966 as the regional professional journal of the medical doctors of the Bosnian Krajina region. This event coincided with the celebration of the $80^{\text {th }}$ anniversary of the General Hospital in Banja Luka ${ }^{2}$, whose brief history was outlined by the founding editor Professor Andrija Mikeš. ${ }^{3}$ All the editors - eight so far - gave their contribution to the advancement of the journal. Their list and the duration of their stay in office of the Editor-in-Chief, Scripta Medica (Banja Luka) is contained in Table 1.

In reality, Professor Bogdan Žigić had effectively served as an editor for "only" 15 years, since the journal temporarily ceased to be published during the four war years (1991-1994). Their photographs are contained in Figure 1. 


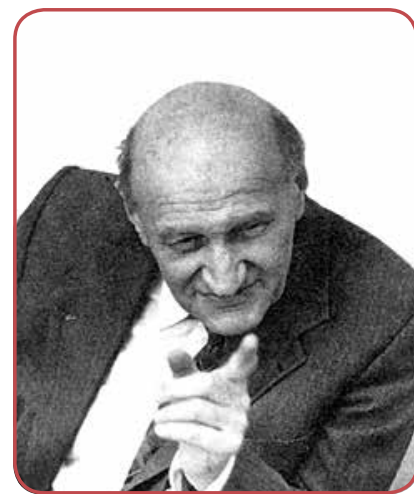

Professor Andrija Mikeš Editor 1966-1968

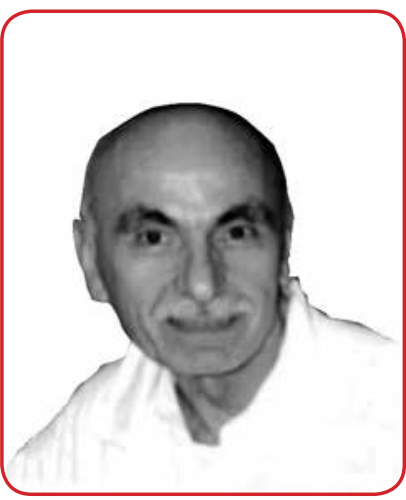

Professor Bogdan Žigić Editor 1991-2009

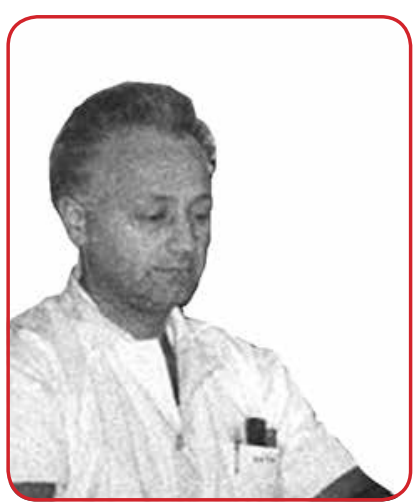

Dr Dragomir Todorović Editor 1969-1971

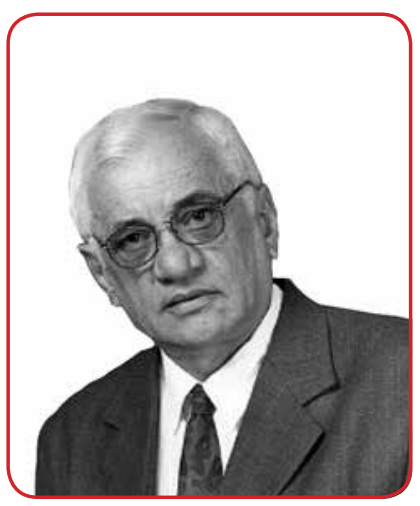

Professor Rajko Igić Editor 2010-2013

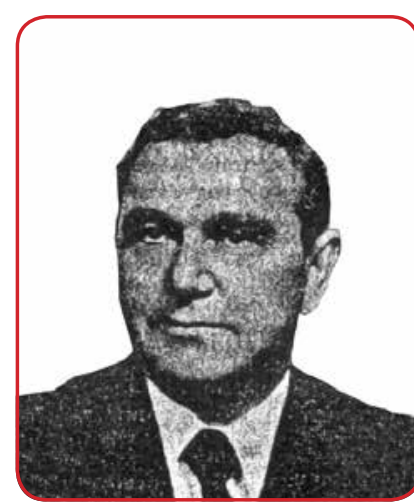

Assist. Prof. Zvonimir Klepac Editor 1972-1974

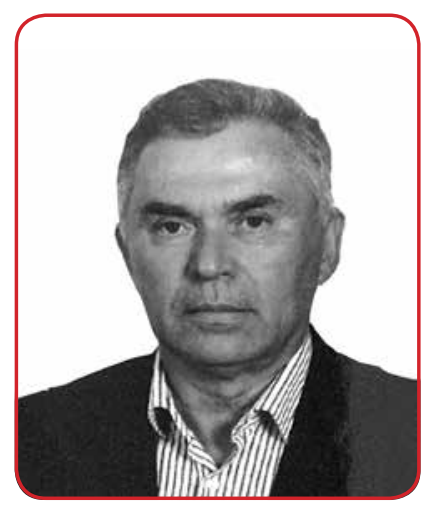

Professor Predrag Grubor Editor 2014-2018

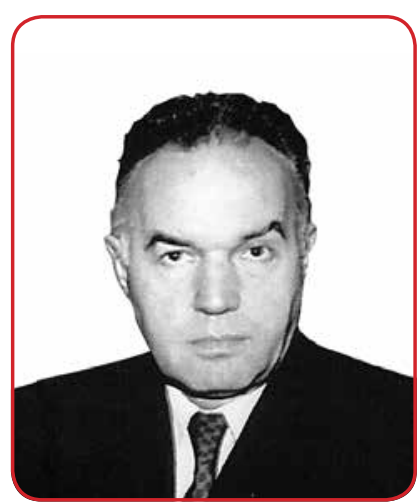

Professor Branko Pikula Editor 1975-1990

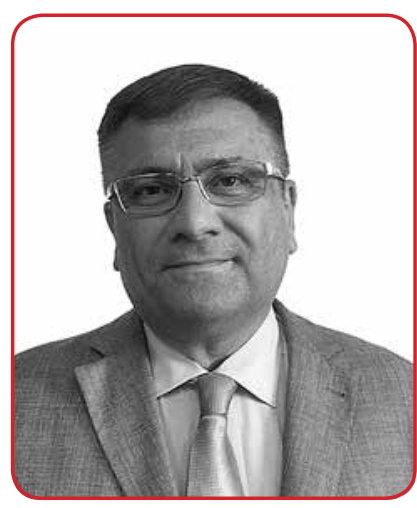

Professor Miloš P Stojiljković Editor 2018-

Figure 1: Photographs of all editors-in-chief of the Scripta Medica (Banja Luka).

A total of 1,223 articles in 85 issues have been published so far (Table 2).

A typical issue of the Scripta Medica (Banja Luka) contained 12 articles (range 1-64).

Distribution of various types of articles is contained in Table 3.

The dominant types of articles were original (29\%), professional (19\%), reviews of important

Table 1: Editors-in-Chief of the Scripta Medica (Banja Luka)

\begin{tabular}{|c|c|c|c|}
\hline Num. & Title, first name and surname & $\begin{array}{l}\text { Period } \\
\text { in office }\end{array}$ & $\begin{array}{l}\text { Number } \\
\text { of years } \\
\text { in office }\end{array}$ \\
\hline 1 & Professor Andrija Mikeš & 1966-1968 & 3 \\
\hline 2 & Dr Dragomir Todorović & $1969-1971$ & 3 \\
\hline 3 & Assist. Prof. Zvonimir Klepac & $1972-1974$ & 3 \\
\hline 4 & Professor Branko Pikula & $1975-1990$ & 16 \\
\hline 5 & Professor Bogdan Žigić & $1991-2009$ & 19 \\
\hline 6 & Professor Rajko Igić & $2010-2013$ & 4 \\
\hline 7 & Professor Predrag Grubor & 2014-2018 & 5 \\
\hline 8 & Professor Miloš P Stojiljković & 2018- & $1+$ \\
\hline
\end{tabular}

Table 2: Structure of articles per issue

\begin{tabular}{|c|c|}
\hline Parameter & Number \\
\hline No. of available issues & 85 \\
\hline No. of articles & 1,223 \\
\hline Mean No. per issue & 14.39 \\
\hline SD & 9.04 \\
\hline Min & 1 \\
\hline $\operatorname{Max}$ & 64 \\
\hline Median & 12 \\
\hline
\end{tabular}

articles published elsewhere (14\%) and case reports (12\%), with the other categories occurring less frequently.

Statistical data on the main elements of individual articles are given in Table 4.

Typically, an article published in the journal had two authors (range 1-15), was 4-pages-long (range 1-34) and cited 8 references range 0-238).

What is more important than these impressive numbers, is continuous advancement of the journal that has become increasingly international over the time. It started to publish articles mainly 
Table 3: Types of articles published in Scripta Medica (Banja Luka)

\begin{tabular}{|c|c|c|}
\hline Type of article & Number & Percent \\
\hline Editorial & 225 & 2.04 \\
\hline Original & 349 & 28.54 \\
\hline Professional & 235 & 19.22 \\
\hline Review & 43 & 3.52 \\
\hline History of medicine & 4 & 0.33 \\
\hline Letter to the editor & 28 & 2.29 \\
\hline Current topic & 62 & 5.07 \\
\hline Case report & 148 & 12.10 \\
\hline Special & 23 & 1.88 \\
\hline Book review & 81 & 6.62 \\
\hline Congress review & 39 & 3.19 \\
\hline Article review & 174 & 14.23 \\
\hline In memoriam & 12 & 0.98 \\
\hline Total & 1,223 & 100.00 \\
\hline
\end{tabular}

Table 4: Characteristics of articles published in Scripta Medica (Banja Luka)

\begin{tabular}{lccc}
\hline Parameter & Pages & Authors & References \\
\hline Number & 5,344 & 3,092 & 13,174 \\
\hdashline Mean & 4.38 & 2.53 & 10.79 \\
\hdashline SD & 3.01 & 2.00 & 13.82 \\
\hdashline Min & 1 & 1 & 0 \\
\hdashline Max & 34 & 15 & 238 \\
\hdashline Median & 4 & 2 & 8 \\
\hline
\end{tabular}

in English since 2010, all in English with abstracts in Serbian since October 2018 and in English only since 2019. The composition of the International Advisory Board of the journal also proves its aspirations towards international recognition. In order to achieve this, the Scripta Medica (Banja Luka) adopted a SCIndeks editorial platform to assist the communication with the authors and the reviewers.

Out of 49 manuscripts received in the year 2019, a total of 32 articles were published in four issues of volume 50, 2019. With 17 rejected manuscripts, the journal keeps a strict rejection rate of $35 \%$. The composition of articles published in the volume 50 is contained in Table 5 .

It is clear that $47 \%$ of the published articles belong to the most prestigious category - original articles, followed by case reports (16\%) and editorials (13\%).

To conclude, 50 volumes of the journal Scripta Medica (Banja Luka) give us reason to be proud with what has been achieved so far, but also represent a serious obligation for the current Editorial Board on our way of gaining its full international
Table 5: Structure of articles published in the Scripta Medica (Banja Luka), volume 50, 2019

\begin{tabular}{|c|c|c|c|c|c|c|}
\hline \multirow[t]{2}{*}{ Type of article } & \multicolumn{4}{|c|}{ Issue No. } & \multicolumn{2}{|c|}{ Total, volume 50} \\
\hline & & & & 4 & Number & Percent \\
\hline Editorial & 1 & 1 & 1 & 1 & 4 & 12.50 \\
\hline Original & 4 & 5 & 3 & 3 & 15 & 46.88 \\
\hline Professional & & 1 & 1 & & 2 & 6.25 \\
\hline Review & 1 & & & & 1 & 3.13 \\
\hline History of medicine & & & & 1 & 1 & 3.13 \\
\hline Current topic & & & 2 & & 2 & 6.25 \\
\hline Case report & 1 & 1 & 1 & 2 & 5 & 15.63 \\
\hline Special & 1 & & & 1 & 2 & 6.25 \\
\hline Total & 8 & 8 & 8 & 8 & 32 & 100.00 \\
\hline
\end{tabular}

recognition. Along these lines is our application for the coverage by the Directory of Open Access Journals (DOAJ) earlier this month. There were two attempts to enter the Medline/PubMed coverage so far, in $2011^{4}$ and in $2016,{ }^{5}$ but both of them were unsuccessful. Our intention is to try to achieve this valuable goal by building a truly international Editorial Board, by attracting prestigious authors from abroad to entrust their manuscripts to the Scripta Medica (Banja Luka) and through the improvement of the international visibility of the journal.

\section{ACKNOWLEDGEMENTS}

The author is indebted to: Professor Miroslav Petković, former Technical Editor of Scr Med (BL), Mr Slaviša Zimonja, the Chief Librarian and Mr Siniša Petković, IT Manager, for providing the documents and photographs necessary for completion of this article.

\section{CONFLICT OF INTEREST}

None.

\section{REFERENCES}

1. Grubor P. [Editor's Letter - 50 years of Scripta Medica]. Scr Med (Banja Luka) 2016;47(1):6. Serbian.

2. Editorial Board. [In occasion of the first issue of our Journal]. Scr Med (Banja Luka) 1966;1(1):5. Serbo-Croatian.

3. Mikeš A. [Eightieth anniversary of the General Hospital of Banja Luka]. Scr Med (Banja Luka) 1966;1(1):613.Serbian.

4. Skrobić M, Trbojević S, Gajanin R. [Conditions for entering of a biomedical journal into MEDLINE database of biomedical data]. Scr Med (Banja Luka) 2013;44(2):110-1. Serbian.

5. Grubor P. Editor's letter. Scr Med (Banja Luka) 2017;48(2):95. 